\title{
Management of Riga-Fede disease: A Case Report
}

\author{
A Alahmari and Albatool Saad Alahmari*
}

Prince Sultan Military Medical City, Saudi Arabia, Riyadh

*Corresponding author: Albatool Saad Alahmari, Institute of Dental Research, Prince Sultan Military Medical City, Saudi Arabia, Riyadh, Tel: +966545510103; E-mail: Dr.albatoool@gmail.com

Received date: January 02, 2017; Accepted date: Feburary 15, 2017; Published date: February 21, 2017

Copyright: ( 2017 Alahmari A, et al. This is an open-access article distributed under the terms of the Creative Commons Attribution License, which permits unrestricted use, distribution, and reproduction in any medium, provided the original author and source are credited.

\begin{abstract}
Riga-fede disease is a rare pediatric condition in which chronic lingual ulceration results from repetitive trauma. Ventral surface of tongue is often the most common site affected. The natal and neonatal teeth have often beaning reported to cause ulceration on the ventral surface of the tongue in neonates and infants. In the present case report 20 days Old female infant presented by parents to the department of endodontic dentistry with Chief complain of an ulcerated area on the ventral surface of tongue, and difficulty in Suckling. Clinical examination revealed a tooth with sharp incisor edge and grade two Mobility. The ventral surface of the tongue showed a $5 \times 8 \mathrm{~mm}$ ulcer extending from under border of the tongue to lingual frenulum. Feeding and nutrition of the baby was getting affected. Conservative treatment was not effective and was causing delay in the healing In the present case, the extraction of neonatal teeth was selected as treatment of choice, which gave improvement and normalization of feeding. At the follow-up, we confirmed that the lesion was resolved and infant was feeding normally.
\end{abstract}

Keywords: Riga-fede disease; Natal teeth; Neonatal teeth; Ulcerated lesion; Saudi arabia

\section{Introduction}

Riga-Fede disease first described by Antonio Riga in 1881, with subsequent histological examinations by Francesco Fede in 1890 [1], is a rare pediatric condition in which chronic lingual ulceration results from repetitive trauma. Ventral surface of tongue is often the site affected [2] Presentation appears to be bimodal, coinciding with natal (present at birth) or neonatal teeth (erupting during the first 30 days of life), and eruption of the primary teeth. Classification into two discrete groups aids etiological identification. 'Early' cases (before six months of age) are related to natal or neonatal teeth, which often present with hypo plastic enamel underdeveloped roots, with resultant early mobility. 'Late' cases (six months of age and older) occurs with primary dentition, are frequently habitual, and may be related to neurological or developmental disorder.

Neonatal teeth or underlying neuro-developmental disorders, which include Down syndrome, Encephalopathy, microcephaly, cerebral palsy, are described as causative or associated factors [3]. Natal teeth are not common; the prevalence ranges from one in 2000 to 1 in 3000 live births and are commonly lower central incisors [4] it occurs in babies less than two years of age. Commonly ulcer is present on the tongue (60\% of the lesions), but other areas such as lip, palate, gingiva, vestibular mucosa and floor of the mouth may be the ulcer site [5]. It is a benign mucosal ulcer [6]. However raised edges of Riga-Fede disease often resemble a malignant process. Alertness of this benign condition is important, as it will avoid excessive anxiety and biopsy [7-8]. Both sexes are equally affected. Differential diagnosis includes infective and neoplastic conditions. Histological diagnosis is required when the symptoms fail to resolve with standard management. Management extraction of natal teeth is recommended due to risk of aspiration or interference with breast-feeding.

\section{Case Report}

20 days old female infant presented by parents to the department of pedodontics dentistry with chief complain of ulcerated area on the ventral surface of tongue. The mother of the baby reported that there is difficulty in suckling and that there was an inappropriate and incomplete nursing. Clinical examination revealed a tooth with sharp incisal edge and grade two mobility. The ventral surface of the tongue showed a $5 \times 8 \mathrm{~mm}$ ulcer extending from under border of the tongue to lingual frenulum (Figure 1). Baby was otherwise in good health. There was no regional lymphadenopathy. The intraoral mucosa revealed no other lesions. The family history was negative also for developmental disorders and congenital syndromes.

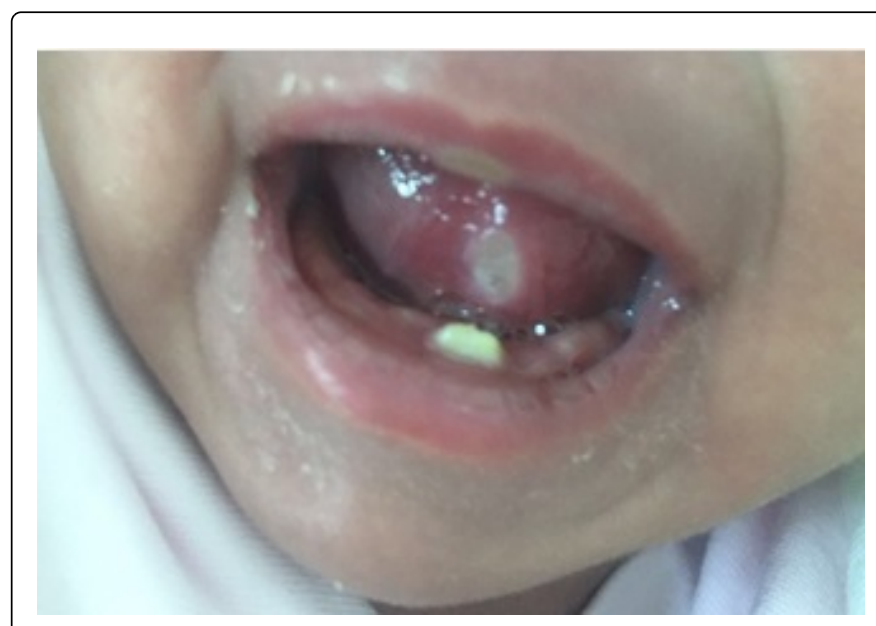

Figure 1: The ventral surface of the tongue showed a $5 \times 8 \mathrm{~mm}$ ulcer extending from under border of the tongue to lingual frenulum.

A clinical diagnosis of Riga-Fede disease due to repetitive trauma resulting from to and fro movements of the tongue against anterior 


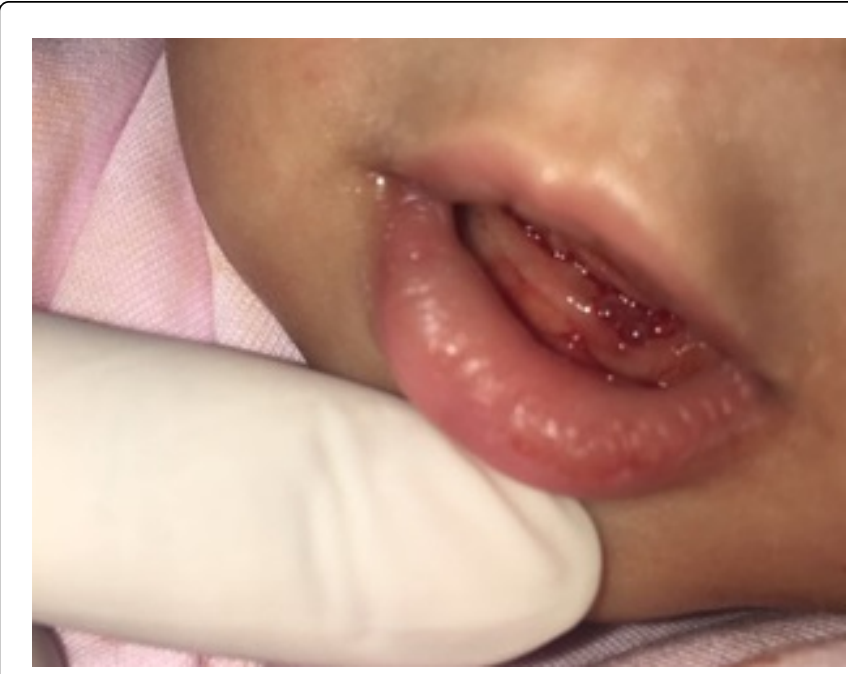

Figure 2: The troubling tooth was removed under local anesthesia.

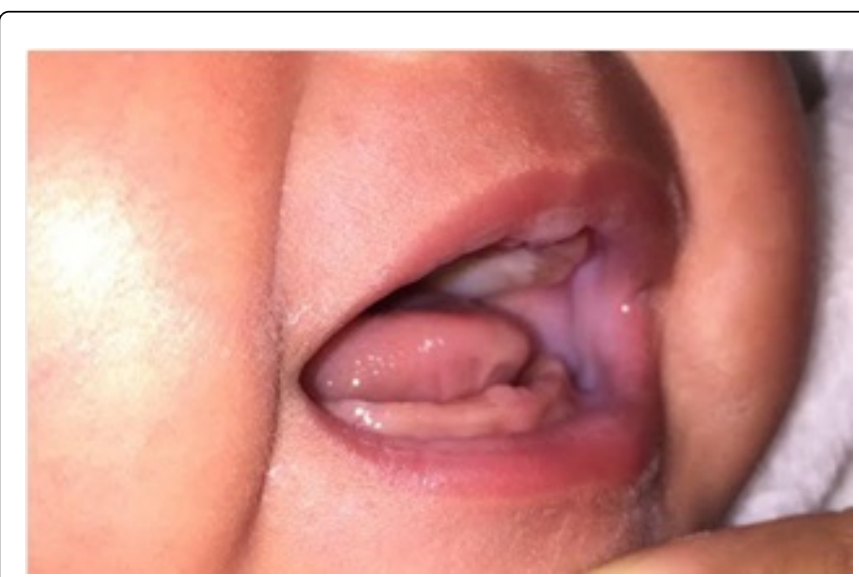

Figure 3: Follow-up revealed that child was feeding normally.

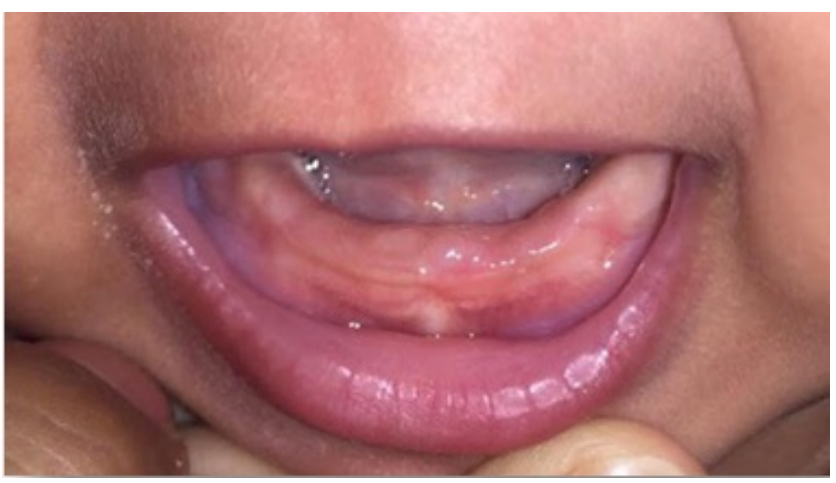

Figure 4: Ulcer healed.

natal teeth was made. Written informed consent was obtained from the patient's parents for publication of this case report and the accompanying images.
Conservative treatment showed slow heeling. Thus extraction of tooth was chosen as treatment option for the rapid resolution of the lesion and for the limited risk of inadequate feed and nutrition intake. The troubling tooth was removed under local anesthesia (Figure 2). Follow-up revealed that child was feeding normally. The ulcer healed (Figures 3 and 4).

\section{Discussion}

In the present study the baby was 20 days old female. Literature reveals that less than $2 \mathrm{yrs}$ is the frequent age at the presentation of Riga-Fede disease. Manouri P Senanayake [7] reported Riga-Fede disease in a 18 months old baby while Domingues CJ [4] reported two years old baby with Riga-Fede disease. In the present study the Ulcer was painful on palpation [9]. Similarly to the present study, The ulceration was painful in a case reported by Costacurta et al. [10] in present case report family history was negative for developmental disorders and congenital syndromes. Similar finding was reported by previous study [10].

The literature reveals that occasionally one in 2000 babies are born with one or two teeth (known as natal teeth) already visible in the gum [11].

In the present case only single tooth, with small ulcer $5 \times 8 \mathrm{~mm}$ in diameter was found on the tongue. While, Costacurta et al. reported presence of two crowns of neonatal teeth with larger ulcer $13 \mathrm{~mm}$ in diameter [10].

In case of mild to moderate irritation of the tongue, conservative treatment such as smoothing the incisal edge with an abrasive instrument is advocated. Alternative a small increment of composite may be bonded to the incisal edge. Extraction of troubling tooth may be needed to alleviate feeding difficulties. In the present case, The extraction of neonatal teeth was selected as treatment of choice, which gave improvement and normalization of feeding.

\section{Conclusion}

Present case report revealed that RFD occurred in very young 20 days old baby without any associated syndrome the conservative treatment was not effective with delay in the heeling. The extraction of neonatal teeth was selected as treatment of choice, which gave improvement and normalization of feeding. Early detection of RFD is desired to avoid, inadequate nutrition intake by the infant and growth retardation.

\section{References}

1. Eley KA, Watt-Smith PA, Watt-Smith SR (2010) Deformity of the tongue in an infant: Riga-Fede disease. Pediatric Child Health 15: 581-582.

2. Sharma N, Chander S, Soni S, Singh S, Chodhary MG (2012) Riga-Fede disease due to neonatal tooth: a case report. Int J Oral MaxillofacPathol 3: 43-44.

3. Baghdadi ZD (2002) Riga-Fede disease: association with microcephaly. Int J of Paediatr Dent 12: 442-445.

4. Domingues CJ, Herrera A, Fernandez CP, Garcia BB, Camacho F (2007) Riga-Fede disease associated with postanoxic encephalopathy and trisomy 21: a proposed classification. PediatrDermatol 24: 663-665.

5. Joseph BK, BairavaSundaram D (2010) Oral traumatic granuloma: report of a case and review of literature. Dent Traumatol 26: 94-97.

6. Ceyhan AM, Yildirim M, Basak PY, Akkaya VB, Ayata A (2009) Traumatic lingual ulcer in a child: Riga-Fede disease. Clin Exp Dermatol 34: $186-188$ 
Citation: Alahmari A and Alahmari AS (2017) Management of Riga-Fede disease: A Case Report. Dentistry 7: 413. doi: $10.4172 / 2161-1122.1000413$

Page 3 of 3

7. Manouri PS, Irantha K (2014) Persistent lingual ulceration (Riga-Fede disease) in an infant with Down syndrome and natal teeth: a case report. J Med Case Rep 8: 283.

8. Baroni A, Capristo C, Rossiello L, Faccenda F, Satriano RA (2006) Lingual traumatic ulceration (Riga-Fede disease). Inter J Dermatol 45: 1096-1097.
9. Hegde RJ (2005) Sublingual traumatic ulceration due to neonatal teeth (Riga-Fede disease). J Indian Soc Pedo Prev Dent 23: 51-52.

10. Costacurta M, Maturo P, Docimo R (2012) Riga-Fede disease and neonatal teeth. Oral Implantol (Rome) 5: 26-30.

11. Anegundi RT, Sudha P, Kaveri H, Sadanand K (2002) Natal and neonatal teeth: A report of four cases. J Indian Soc Pedod Prev Dent. 20: 86-92. 